\title{
Neurocritical care complications and interventions influence the outcome in aneurysmal subarachnoid hemorrhage
}

\author{
Alexander Hammer ${ }^{1 *}$, Frank Erbguth², Matthias Hohenhaus ${ }^{3}$, Christian M. Hammer ${ }^{4}$, Hannes Lücking ${ }^{5}$, \\ Markus Gesslein ${ }^{6}$, Monika Killer-Oberpfalzer ${ }^{7}$, Hans-Herbert Steiner ${ }^{1}$ and Hendrik Janssen ${ }^{8}$
}

\begin{abstract}
Background: This observational study was performed to show the impact of complications and interventions during neurocritical care on the outcome after aneurysmal subarachnoid hemorrhage (SAH).

Methods: We analyzed 203 cases treated for ruptured intracranial aneurysms, which were classified regarding clinical outcome after one year according to the modified Rankin Scale (mRS). We reviewed the data with reference to the occurrence of typical complications and interventions in neurocritical care units.

Results: Decompressive craniectomy (odds ratio $21.77 / 6.17 ; p<0.0001 / p=0.013$ ), sepsis (odds ratio $14.67 / 6.08$ $; p=0.037 / 0.033$ ) and hydrocephalus (odds ratio $3.71 / 6.46 ; p=0.010 / 0.00095$ ) were significant predictors for poor outcome and death after one year beside "World Federation of Neurosurgical Societies" (WFNS) grade (odds ratio $3.86 / 4.67 ; p<0.0001 / p<0.0001$ ) and age (odds ratio $1.06 / 1.10 ; p=0.0030 / p<0.0001$ ) in our multivariate analysis (binary logistic regression model).
\end{abstract}

Conclusions: In summary, decompressive craniectomy, sepsis and hydrocephalus significantly influence the outcome and occurrence of death after aneurysmal SAH.

Keywords: Intracranial aneurysm, Subarachnoid hemorrhage, Vascular disorders, Outcome, Neurocritical care, Decompressive craniectomy

\section{Background}

Outcome of aneurysmal subarachnoid hemorrhage $(\mathrm{SAH})$ is mainly attributed to direct effects of SAH, ischemic cerebral infarction and aneurysm rebleeding [13]. Besides the initial clinical state, age and the aneurysm size are also known to play an important role as well as delayed cerebral ischemia [4-9].

\footnotetext{
* Correspondence: alexander.hammer@klinikum-nuernberg.de

Portions of this work were presented in form of an oral presentation at the "Annual Meeting of the German Society of Neurosurgery" (DGNC), Würzburg Germany, May 13, 2019.

'Department of Neurosurgery, Paracelsus Medical University, Breslauer Straße 201, 90471, Bavaria, Nuremberg, Germany

Full list of author information is available at the end of the article
}

Moreover the effect of the choice of intervention regarding the outcome has been a controversial subject for years among specialists for endovascular and microsurgical aneurysm treatment [10]. Spetzler et al. confirmed with the 6-year results of the "Barrow Ruptured Aneurysm Trial" superior outcomes of endovascular coil embolization compared to microvascular clipping regarding aneurysms of the posterior circulation, but also revealed little difference in outcome between the 2 treatment methods for anterior circulation aneurysms in the long run [11].

Comorbidities and life style risk factors also seem to influence the outcome of SAH but published results, especially regarding hypertension and smoking, remain contradictory $[12,13]$. Recently published investigations

(C) The Author(s). 2021 Open Access This article is licensed under a Creative Commons Attribution 4.0 International License, which permits use, sharing, adaptation, distribution and reproduction in any medium or format, as long as you give appropriate credit to the original author(s) and the source, provide a link to the Creative Commons licence, and indicate if changes were made. The images or other third party material in this article are included in the article's Creative Commons licence, unless indicated otherwise in a credit line to the material. If material is not included in the article's Creative Commons licence and your intended use is not permitted by statutory regulation or exceeds the permitted use, you will need to obtain permission directly from the copyright holder. To view a copy of this licence, visit http://creativecommons.org/licenses/by/4.0/. The Creative Commons Public Domain Dedication waiver (http://creativecommons.org/publicdomain/zero/1.0/) applies to the data made available in this article, unless otherwise stated in a credit line to the data. 
found that smoking and hypertension may act as predictors regarding a good clinical outcome after aneurysmal SAH $[14,15]$.

The impact of treatment on intensive care units (ICU) after SAH is also recognized to be a significant factor regarding the outcome after SAH $[9,16-18]$. Typical SAH related complications like hydrocephalus, pneumonia and sepsis were detected as critical determinants of outcome $[9,16,17]$. Critical care strategies are suggested which focus on maintaining normothermia, normoglycemia and prevention of anemia, as well as the implementation of infection-control measures in order to improve outcome after SAH $[17,18]$.

In this observational study, we investigated complications and interventions after SAH in the intensive care unit and analyzed the effect on the clinical outcome and death after one year. Further we investigated the influence of these factors on the occurrence of pneumonia and tracheostomy.

\section{Methods}

Data were extracted and analyzed from an observational database comprising 203 cases of ruptured intracranial aneurysms from 2012 to 2017 which were treated by the departments of neuroradiology, neurology, anaesthesiology and neurosurgery at the Paracelsus Medical University Nuremberg.

Occlusion of the aneurysms was achieved by microsurgical clipping or endovascular embolization methods (sole coiling, coiling in combination with balloon or stent assisted remodelling or the use of endovascular or intrasaccular flow-diverters). Allocation of the patients to the different treatment branches was part of the standard care of the patients. Patients were included in this study, if the following criteria were fulfilled:

1 Time between aneurysm rupture and treatment < 48 hours.

2 Informed consent from the patient, a patient's relative or the patient's guardian.

3 Verification of SAH with cranial computed tomography (CT) or lumbar puncture and verification of an associated intracranial aneurysm diagnosed in most cases by digital subtraction angiography, alternatively by $\mathrm{CT}$ angiography if an immediate operation had to be performed.

4 Patient survival until completion of aneurysm treatment.

Our local institutional review board stated, that for this study no submission to the ethics committee is necessary (Ethik-Kommission der Bayerischen Landesärztekammer Mühlbaurstraße 16, 81677 München ; reference number: 2019-018 fm/h). The study was performed in accordance with the ethical standards laid down in the 1964 declaration of Helsinki and its later amendments. Informed consent of the patients or their relatives was obtained at least verbally during the initial hospital stay or during the telephone interview in the follow up because written consent was not always available in terms of the initial hospital stay or follow up. The local institutional review board approved this procedure and waived a patient informed consent, as the data is fully anonymized (Ethik-Kommission der Bayerischen Landesärztekammer, Mühlbaurstraße 16, 81677 München ; reference number: 2019-018 fm/h). One patient refused to participate in this study and therefore was excluded from our collective (1 of 204). For our analysis 203 cases of SAH were available.

Outcome was measured using the modified Rankin Scale (mRS), which was prospectively evaluated by telephone interview one year after SAH. With the usage of the mRS, occurrence of death and a follow-up time after 12 months, our methods adhere to the recommendations of Stienen et al. regarding outcome assessment in order to improve comparability of results [19]. We categorized outcome results into poor clinical outcome $(m R S \geq 3)$ and good clinical outcome (mRS 0-2) to evaluate the associations of intensive care complications and to make a comparison to other studies possible, which use the same dichotomization. This separation of outcome measures was commonly used in large randomized trials dealing with treatment of aneurysmal SAH $[10,11]$. Moreover, we conducted another dichotomization of the outcome data (survival after one year: mRS 1-5 versus occurrence of death after one year: $\mathrm{mRS}=6$ ) in order to present the major impact of the occurrence of death regarding its association with some of our analyzed neurocritical care complication data. With intent of finding associations of intensive care complications or interventions with outcome parameters, we collected related data during the stay in the intensive care unit (ICU). This included the occurrence of pneumonia, sepsis, hydrocephalus, shunt placement, diabetes insipidus, tracheostomy, and decompression. Cases with hydrocephalus were initially treated with external ventricular drainages (EVD). Over the course of the stay either the EVD was removed if possible or the shunt implantation was indicated and was executed as early as possible with special awareness regarding signs of infection. There were some cases of late onset of hydrocephalus and shunt placement, which occurred after stay on intensive care. These few cases were recorded until one year after SAH via telephone interview and further medical records, if they were associated with the initial event of SAH.

Decompressive craniectomy was performed in cases of raised intracranial pressure, caused by general brain edema, intracerebral hemorrhage or cerebral ischemia, 
which were not sufficiently controllable by conservative intensive care treatment. Diagnostic imaging as well as clinical parameters were grounds for decompression. Decompression techniques included decompressive hemicraniectomy, bifrontal craniectomy and decompression of the posterior cranial fossa.

The "cut-off" time-point of the tracheostomy-procedure was 14 days. In terms of a conceivably longer stay on ICU (because of reasons like reduced consciousness, dysphagia or weaning-problems) the tracheostomy was executed after approximately one week (with preference of a percutaneous dilatation tracheostomy).

In part data of this patient cohort were analyzed for different aspects and published previously [15, 20-23].

\section{Statistics}

Statistical analysis was performed using SPSS version 21 software (SPSS Inc., Cary, SC) for descriptive statistics and the results of binary logistic regression analysis. A maximum of 10 independent variables (covariates) in the binary logistic regression were included. Number of cases of every independent variable (covariate) was $>15$. The Nagelkerke R Square and Hosmer and Lemeshow test value were stated along with every executed binary regression analysis. P-values below 0.05 indicated statistical significance.

\section{Results}

Tables regarding the baseline data and the outcome data were published previously [15]. For the baseline data all 203 cases of SAH were available, outcome data were recorded from 199 to 203 patients.

Table 1 summarizes the complications (pneumonia, sepsis, hydrocephalus, diabetes insipidus) and interventions (shunt procedure because of ongoing or late onset hydrocephalus, tracheostomy, decompressive craniectomy) during stay on intensive care. A considerable part of our collective suffered from pneumonia $(43.8 \%)$ and hydrocephalus $(51.7 \%)$. Less frequent complications were sepsis $(7.9 \%)$ and diabetes insipidus $(13.8 \%)$.

Table 1 Complications and Interventions on Intensive Care Unit

\begin{tabular}{lcc}
\hline Complications / Interventions & $\mathbf{n}$ & Percentage \\
\hline Pneumonia & 89 & $43.8 \%$ \\
Sepsis & 16 & $7.9 \%$ \\
Hydrocephalus & 105 & $51.7 \%$ \\
Shunt & 30 & $14.8 \%$ \\
Diabetes insipidus & 28 & $13.8 \%$ \\
Tracheostomy & 62 & $30.5 \%$ \\
Decompressive craniectomy & 43 & $21.2 \%$ \\
Total & 203 & $100.0 \%$ \\
\hline
\end{tabular}

Data of complications and interventions were available for all 203 cases of SAH.

\section{Influence of complications and interventions on the outcome after one year}

Outcome data were dichotomized in "good outcome" $(\mathrm{mRS}=0-2)$ and "poor outcome" $(\mathrm{mRS}=3-6)$ and used as the dependent variable in binary logistic regression analysis. Included baseline characteristics as independent variables were sex, age and WFNS grade. The Nagelkerke R Square value (0.682) and the Hosmer and Lemeshow tests (0.855) showed good quality for the model of our test regarding the prediction of poor outcome.

Age $(p=0.0030)$, WFNS grade $(p<0.0001)$, sepsis $(p=$ $0.037)$, hydrocephalus $(p=0.010)$ and decompressive craniectomy $(p<0.0001)$ showed statistical significance regarding the prediction of outcome after one year. A very strong influence on the prediction of outcome after one year was attributed to decompressive craniectomy (odds ratio (OR) 21.77) and sepsis (OR 14.67). Strong influence was verifiable for the WFNS grade (OR 3.86) and hydrocephalus (OR 3.71). Age had a mild influence regarding the prediction of outcome after one year (OR 1.06). All other independent variables did not reach significance (Table 2).

\section{Influence of complications and interventions on the occurrence of death after one year}

Using binary logistic regression methods, we investigated predictors for death one year after SAH. We dichotomized status of death in our available mRS data (mRS $0-5=$ "alive"; $\operatorname{mRS} 6=$ "dead"). The Nagelkerke R Square value was 0.589 and the Hosmer and Lemeshow test value 0.486 .

This analysis included the same significant predictors for death after one year as for the outcome after one year: Age $(p<0.0001)$, WFNS grade $(p<0.0001)$, sepsis $(p=0.033)$, hydrocephalus $(p=0.00095)$ and decompressive craniectomy $(p<0.013)$ showed statistical significance regarding the prediction of death after one year. But it also revealed additional significant predictors of survival after one year, in particular the shunting procedure $(p=0.025)$ and tracheostomy $(p=$ 0.0016). Hydrocephalus (OR 6.46), sepsis (OR 6.08), decompressive craniectomy (OR 6.17) and WFNS grade (OR 4.67) had a strong influence and age a mild influence on the occurrence of death after one year (OR 1.10). With the shunting procedure (OR 0.18 ) and tracheostomy (OR 0.09) we revealed strong predictors of survival after one year. Sex, pneumonia and diabetes insipidus did not reach statistical significance (Table 3). 
Table 2 Prediction of Outcome after one Year

\begin{tabular}{|c|c|c|c|}
\hline Risk factors & Odds ratio & $95 \%$ Confidence interval & $\mathbf{p}$ \\
\hline Sex & 1.40 & $0.55-3.56$ & 0.49 \\
\hline Age & 1.06 & $1.02-1.10$ & 0.0030 \\
\hline WFNS Grade & 3.86 & $2.23-6.68$ & $<0.0001$ \\
\hline Pneumonia & 2.68 & $0.925-7.75$ & 0.069 \\
\hline Sepsis & 14.67 & $1.18-181.91$ & 0.037 \\
\hline Hydrocephalus & 3.71 & $1.36-10.08$ & 0.010 \\
\hline Shunt & 1.04 & $0.25-4.36$ & 0.96 \\
\hline Diabetes insipidus & 0.40 & $0.098-1.60$ & 0.19 \\
\hline Tracheostomy & 0.35 & $0.094-1.29$ & 0.11 \\
\hline Decompressive craniectomy & 21.77 & $4.97-95.36$ & $<0.0001$ \\
\hline
\end{tabular}

\section{Influence of complications and interventions on the occurrence of pneumonia}

Statistical significance regarding the prediction of pneumonia during stay on intensive care was reached by the independent variables decompressive craniectomy $(p=$ 0.0039 ; OR 4.45), hydrocephalus ( $p=0.0028$; OR 3.49), WFNS grade $(p=0.00017$; OR 2.23) and age $(p=0.041$; OR 1.03). Sex, shunting procedure, sepsis and diabetes insipidus did not show significant values (Table 4). For this analysis the Nagelkerke R Square value was 0.522 and the Hosmer and Lemeshow test value 0.618.

\section{Influence of complications and interventions on the occurrence of tracheostomy}

With tracheostomy as the dependent variable and the complications and interventions on ICU as the independent variables binary logistic regression analysis was executed. Nagelkerke R Square (0.685) and the Hosmer and Lemeshow test $(0.817)$ showed good values for our model regarding prediction of tracheostomy. Significant variables were WFNS grade $(p=0.043)$, pneumonia $(p<$ $0.0001)$, sepsis $(p<0.031)$, shunting procedure $(p=$ $0.00076)$ and decompressive craniectomy $(p=0.00041)$. Shunting procedure (OR 12.80), pneumonia (OR 10.02) and decompressive craniectomy (OR 8.28) had the strongest association regarding prediction of tracheostomy, followed by sepsis (OR 6.09). WFNS grade had a comparatively low impact on prediction of tracheostomy (OR 1.82). Sex, age, hydrocephalus and diabetes insipidus were no significant predictors of tracheostomy (Table 5).

\section{Discussion}

With this study we analyzed the impact of complications and interventions in intensive care units on the outcome

Table 3 Prediction of Death after one Year

\begin{tabular}{lll}
\hline Risk factors & Odds ratio & 95 $\%$ Confidence interval \\
\hline Sex & 1.24 & $0.48-3.22$ \\
Age & 1.10 & $1.05-1.15$ \\
WFNS Grade & 4.67 & $2.49-8.75$ \\
Pneumonia & 0.64 & $0.20-2.07$ \\
Sepsis & 6.08 & $1.16-32.04$ \\
Hydrocephalus & 6.46 & $2.14-19.51$ \\
Shunt & 0.18 & 0.0001 \\
Diabetes insipidus & 0.28 & 0.46 \\
Tracheostomy & 0.09 & $0.058-1.35$ \\
Decompressive craniectomy & 6.17 & 0.033 \\
\hline
\end{tabular}

Binary logistic regression was performed as a multivariate analysis with dichotomized status of death ( 0 = "alive"; 1 = "dead") as the dependent variable and sex, age, WFNS grade, pneumonia, sepsis, hydrocephalus, shunt, diabetes insipidus, tracheostomy and decompressive craniectomy as independent variables (covariates) 
Table 4 Predictors of Pneumonia during stay on Intensive Care Unit

\begin{tabular}{|c|c|c|c|}
\hline Risk factors & Odds ratio & $95 \%$ Confidence interval & $p$ \\
\hline Sex & 0.78 & $0.36-1.68$ & 0.52 \\
\hline Age & 1.03 & $1.00-1.06$ & 0.041 \\
\hline WFNS Grade & 2.23 & $1.47-3.40$ & 0.00017 \\
\hline Hydrocephalus & 3.49 & $1.54-7.89$ & 0.0028 \\
\hline Shunt & 2.95 & $0.90-9.73$ & 0.075 \\
\hline Sepsis & 5.50 & $0.97-31.04$ & 0.054 \\
\hline Diabetes insipidus & 0.66 & $0.21-2.04$ & 0.47 \\
\hline Decompressive craniectomy & 4.45 & $1.61-12.26$ & 0.0039 \\
\hline
\end{tabular}

Binary logistic regression was performed as a multivariate analysis with dichotomized status of pneumonia ( $0=$ "no pneumonia"; 1 = "pneumonia") as the dependent variable and sex, age, WFNS grade, hydrocephalus, shunt, sepsis, diabetes insipidus and decompressive craniectomy as independent variables (covariates)

after one year in SAH. Further we found significant predictors of pneumonia and tracheostomy.

Decompressive craniectomy, sepsis and hydrocephalus were significant predictors for poor outcome and death after one year in our collective. Tracheostomies and shunting procedures were associated with survival after one year. Higher WFNS grade, hydrocephalus and decompressive craniectomy were predictors of pneumonia. Tracheostomy was associated with higher WFNS grade, pneumonia, sepsis, shunt procedure and decompressive craniectomy.

\section{Decompressive craniectomy and sepsis as predictors of poor outcome and death after one year}

Decompressive craniectomy (outcome OR 21.77 ; death OR 6.17) and sepsis (outcome OR 14.67 ; death 6.08) were very strong predictors of poor outcome in our analysis.

Surgical decompressive craniectomy is a very invasive approach, but is also a potent manoeuvre to reduce intracranial pressure [24, 25]. It involves severe risks like hydrocephalus, external brain tamponade, sinking skin flap syndrome, seizures, cerebral haemorrhage and paradoxical brain herniation [26-30]. SAH patients suffering from the life-threatening effects of the SAH itself must then additionally overcome the debilitating decompressive craniectomy. Alexander et al. stated that decompressive hemicraniectomy in large middle cerebral artery stroke results in great reductions in mortality, but leads to survival of patients with severe or very severe disability. They judged the benefit of decompressive craniectomy to be questionable, if it reduces frequency of death but induces survival with severe permanent disability [28]. This is particularly a debatable issue in elderly patients $[31,32]$. In analyzed $\mathrm{SAH}$-sub collectives (43 of 744 patients and 79 of 939 patients) who underwent decompressive treatment, the rate of a favourable outcome of the decompressed patients was not convincing (25.6\% and $26.6 \%$ ), however the proportion of poor grade patients according to WFNS was very high $(83.7 \%$ and $77.2 \%)[33,34]$. In our collective decompressed patients had a favourable outcome after one year in $11.9 \%$ ( 5 of 42; one missing because no mRS data after one year was available) with exactly the same proportion of poor grade patients $(83.7 \%, 36$ of 43$)$ according to WFNS. One third of the decompressed patients died (15

Table 5 Factors leading to Tracheostomy during stay on Intensive Care Unit

\begin{tabular}{llll}
\hline Risk factors & Odds ratio & $\mathbf{9 5} \%$ Confidence interval & $\mathbf{p}$ \\
\hline Sex & 1.33 & $0.49-3.60$ & 0.58 \\
Age & 0.99 & $0.96-1.03$ & 0.74 \\
WFNS Grade & 1.82 & $1.02-3.23$ & 0.043 \\
Pneumonia & 10.02 & $3.19-31.41$ & $<0.0001$ \\
Sepsis & 6.09 & $1.18-31.55$ & 0.031 \\
Hydrocephalus & 0.74 & $0.23-2.45$ & 0.63 \\
Shunt & 12.80 & $2.90-56.47$ & 0.00076 \\
Diabetes insipidus & 2.54 & $0.64-10.16$ & 0.19 \\
Decompressive craniectomy & 8.28 & $2.57-26.71$ & 0.00041 \\
\hline
\end{tabular}

Binary logistic regression was performed as a multivariate analysis with dichotomized status of tracheotomia $(0=$ "no tracheostomy"; 1 = "tracheostomy") as the dependent variable and sex, age, WFNS grade, pneumonia, hydrocephalus, shunt, sepsis, diabetes insipidus and decompressive craniectomy as independent variables (covariates) 
of $42,35.7 \%$, one missing). Accordingly, the majority of the decompressed patients survived with a severe to very severe disability $(81.5 \%, 22$ of 27$)$. Our results suggest that decompressive craniectomy strongly predicts death and poor outcome and support the concerns of Alexander et al. [28]. This emphasizes the debate, whether decompressive craniectomy is reasonable for these patients and raises the need for individual decisions by the treating specialists.

The time from the onset of elevated and uncontrollable intracranial pressure to the decompression treatment might be an important factor concerning the outcome [34]. The underlying reason (brain swelling, bleeding or infarction) for the decompressive craniectomy does not seem to be relevant for the rate of favourable outcomes [34].

Sepsis was described as a significant risk factor regarding the outcome after $\mathrm{SAH}$ in previous literature. Dasenbrock et al. report that central venous catheter associated infections were linked with increased likelihood of a poor outcome [16]. Similar statements made Frontera et al.: blood stream infection independently predicted death or severe disability at 3 months [17]. Taufique et al. summarized that poor physical quality of life was associated with sepsis and hydrocephalus after older age and pneumonia [9].

\section{Prediction of tracheostomy and prediction of survival through tracheostomy}

Tracheostomy is a key intervention predicting the survival of the patient up to one year (OR $0.09 ; p=0.0016$ ), although it is not a significant predictor for the quality of life after one year $(p=0.11)$ in our cohort.

There is evidence, that tracheostomy has a direct beneficial impact on the survival of patients suffering from SAH. Ventilation time is subsequently reduced through tracheostomy. Ponfick et al. stated that every day of mechanical ventilation reduces the probability of a beneficial outcome and that tracheotomized patients with cerebrovascular diseases benefit from early inpatient rehabilitation, irrespective of the etiology of vascular brain injury [35]. The guidelines for the management of severe traumatic brain injury state that tracheostomy reduces mechanical ventilation days. However it does not alter rate of pneumonia or mortality in traumatic brain injury patients [36].

WFNS grade (OR $1.82 ; \mathrm{p}=0.043$ ), pneumonia (OR $10.02 ; \mathrm{p}<0.0001$ ), sepsis (OR $6.0 ; \mathrm{p}=0.031$ ), shunting procedure (OR $12.80 ; \mathrm{p}=0.00076$ ) and decompressive craniectomy (OR $8.28 ; \mathrm{p}=0.00041$ ) were significant predictors of tracheostomy in our cohort. All of these variables come along with factors needing a longer ventilation time and therefore tracheostomy.
Szeder et al. analyzed patients with intracerebral hemorrhage and also found the initial clinical status (Glasgow Coma Scale) but also the radiological presence of hydrocephalus as predictors of need for tracheostomy [37]. Another study dealing with predictors of tracheostomy in patients suffering from intracerebral hemorrhage detected hydrocephalus to be a critical factor in prediction of tracheostomy, after volume of intracerebral hemorrhage, presence of chronic obstructive pulmonary disease (COPD) and ganglionic location of the hematoma [38]. In our collective only the subgroup of chronic hydrocephalus (shunting procedure), but not hydrocephalus was associated with tracheostomy.

\section{The role of hydrocephalus after SAH in the prediction of outcome and death after one year}

Consecutive hydrocephalus after the subarachnoid hemorrhage determines the outcome and death after one year in a significant way (outcome: OR $3.71 ; p=0.010-$ death: OR $6.46 ; p=0.00095)$. However, the subgroup of hydrocephalus-patients with chronic hydrocephalus, who required a shunting procedure had no significant effect on the outcome after one year $(p=0.96)$, but was more likely to survive the first year (OR $0.18, p=0.025$ ).

Without adequate treatment by implantation of an external ventricular drainage hydrocephalus is a lifethreatening condition with increased intracranial pressure leading to an impaired clinical state. The consecutive decreased consciousness leads to complications like aspiration, pneumonia and thus extended mechanical ventilation. These factors associated with hydrocephalus might play a critical role in the determination of outcome in the early stage after SAH.

Our findings regarding the role of hydrocephalus on the outcome are well confirmed by the existing literature. Beneš et al. investigated the causes of poor outcome in patients with good-grade subarachnoid hemorrhage and found that the presence of hydrocephalus is a significant predictor of poor Glasgow Outcome Scale scores beneath the factor of age over 60 years [39]. Taufique et al. also saw a determination of outcome through the incidence of hydrocephalus in their cohort [9]. Galea et al. presented a large cohort of 3341 patients suffering from $\mathrm{SAH}$, where the need for a cerebrospinal fluid diversion (OR 3.25 ; $95 \%$ confidence interval (CI) $2.58-4.09 ; p<0.001)$ was an independent predictor of an unfavourable outcome after increasing age, WFNS grade, preoperative rebleeding and delayed cerebral ischemia. They also discuss our mentioned idea of a direct effect of the hydrocephalus causing raised intracranial pressure, besides iatrogenic injury and rehemorrhage [3].

On the one hand the subgroup of patients with chronic hydrocephalus, who required a shunting 
procedure more likely survived the first year (OR 0.18 , $p=0.025$ ) in our collective. Reasons might be beneficial pathomechanisms which come along with the implementation of a cerebrospinal fluid (CSF) drainage. They range from improvement of the clinical grade in poor grade SAH patients by treatment of the raised intracranial pressure to the theory, that CSF drainage can improve cerebral oxygenation and reduce delayed cerebral ischemia (DCI) [40, 41]. The question is whether these positive effects particularly take place in the subgroup of chronic hydrocephalus through a permanent CSF drainage and thereby lead to the survival of the patients.

On the other hand, chronic hydrocephalus and a consecutive shunting procedure had no significant positive influence on the quality of life after one year $(p=0.96)$ in our cohort. Regarding this point existing literature is quite heterogeneous. Wong et al. found that chronic hydrocephalus was significantly associated with poor quality of life after SAH [42]. Poon et al. examined the impact of chronic hydrocephalus on neurological outcome with a 6-month extended Glasgow Outcome Scale score in a more differentiated manner. They detected an association of chronic hydrocephalus with a better extended Glasgow Outcome Scale score among patients with a poor WFNS grading, but in patients with a good WFNS grading, chronic hydrocephalus was associated with a poor extended Glasgow Outcome Scale score [43].

\section{The role of pneumonia and diabetes insipidus in the prediction of outcome and death after one year} In our cohort pneumonia $(\mathrm{p}=0.069$ respectively $\mathrm{p}=0.46)$ and diabetes insipidus $(\mathrm{p}=0.19$ respectively $\mathrm{p}=0.11)$ were no significant predictors of outcome or death after one year. This is in line with a publication of Wartenberg et al. who analyzed 580 patients and had similar outcome data to those of our cohort. Fever, anemia and hyperglycemia were associated with mortality and poor functional outcome, but not pneumonia and diabetes insipidus [18]. However, there are some publications which found a significant association between pneumonia and reduced outcome or poor quality of life $[9,16,17]$. To our knowledge there is no publication describing a significant association between poor outcome after $\mathrm{SAH}$ and diabetes insipidus.

\section{WFNS grade and age as predictors of poor outcome and death after one year}

WFNS grade (outcome OR 3.86 ; death OR 4.67) and age (outcome OR 1.06 ; death OR 1.10) are known predictors of outcome, which have been confirmed in several studies before [4, 7-9].

\section{Standardization of management and outcome measurement after aneurysmal SAH}

In order to minimize varieties of management of cases of aneurysmal SAH, standardized management protocols (SMPs) are useful as they are assumed to improve patient outcomes after subarachnoid hemorrhage. Therefore, outcome measurement, management of acute $\mathrm{SAH}$, early brain injury, DCI and general neurocritical care should be standardized.

A systematic review of Taran et al. aimed to detect the impact of SMPs after SAH [44]. Two randomized control trials and 35 observational studies were therefore included. It was remarkable, that significant limitations like single-center case series with small patient sizes and inconsistent definitions of key terms and outcome reporting practices inhibited a meta-analysis for 6-month mortality and neurologic outcomes and therefore the anticipated effect of SMPs could not be confirmed [44].

In order to overcome systematic issues of incomparability regarding outcome measurement, common data elements have been defined regarding outcomes and endpoints [19]. In these terms the modified Rankin Scale score is recommended, while Death, Glasgow Outcome Scale score, and Glasgow Outcome Scale-extended were classified as supplemental. Timing for long-term outcome assessment is advised to be conducted at 12 months [19].

There are lacking standards regarding ventilation-, monitoring- and sedation-management after aneurysmal SAH, which are also assumed to have effects on the outcome [45]. With the help of a questionnaire ICU practices in aneurysmal SAH in Germany were evaluated and compared to guidelines, if existing. In this study, ICU management after aneurysmal SAH was found to be very heterogeneous. This leads to the conclusion, that evidence in this area of SAHmanagement is insufficient [45]. There is a necessity to define optimal requirements and guidelines of ICU management after SAH, particularly management of ventilation, timing of tracheostomy, sedation and intracranial pressure (ICP) / cerebral metabolism monitoring.

\section{Limitations}

The higher probability of survival of tracheotomized and shunted patients after one year might be a simple result of the imperative of survival regarding the first critical days after SAH. Only patients who survive will get a tracheostomy or shunting procedure. Parts of the data regarding complications and interventions were collected retrospectively. Moreover, our results might have a limited range concerning a generalization, because data was collected at a single-center in middle Europe. Specialization regarding the treatment of SAH and its complications, as well as differences concerning the choice of treatment modalities, treatment capacities and logistical limitations in 
comparison to other hospitals might therefore lead to a bias regarding the generalizability of these observations. More powerful prospective multicenter randomized trials with high patient numbers, which adhere to standardization of outcome measurement and management of aneurysmal SAH, will be needed to confirm our results.

\section{Conclusions}

Beside baseline characteristics (WFNS-grade and age) decompressive craniectomy, sepsis and hydrocephalus strongly influence the outcome and survival in SAH after one year. Tracheostomy and chronic hydrocephalus in terms of a consecutive shunting procedure did not significantly influence the quality of life after one year, but these patients were more likely to survive the first year after SAH. Several factors with influence on the clinical outcome of patients cannot be controlled by therapy. But rapid and decisive treatment of infections, intracranial perfusion and intracranial pressure might influence the frequency of critical complications and interventions and accordingly might lead to a more favorable outcome after SAH. The significance of decompressive craniectomy in SAH seems to be debatable in terms of outcome after one year.

\section{Abbreviations}

95\% Cl: 95\% confidence interval; COPD: Chronic obstructive pulmonary disease; CSF: Cerebrospinal fluid; CT: Computed tomography; DCl: Delayed cerebral ischemia; EVD: External ventricular drainage; ICP: Intracranial pressure; ICU: Intensive care unit; mRS: Modified rankin scale; OR: Odds ratio; SAH: Subarachnoid hemorrhage; SMPs: Standardized management protocols; WFNS: World Federation of Neurosurgical Societies

\section{Acknowledgements}

Our thanks go to all participating departments, especially the Department of Neurology, Nuremberg General Hospital, Germany.

\section{Authors' contributions}

A.H. and H.J.: study conception and design, acquisition of data, analysis and interpretation of data. A.H.: drafting of the manuscript. C.H., H.L., M.G., F.E., M.H. and M.K.: critical revision of the manuscript. H.H.S.: study conception and design, critical revision of the manuscript. All authors have read and approved the manuscript.

\section{Funding}

No funding was received for this research.

\section{Availability of data and materials}

The datasets generated and/or analysed during the current study are not publicly available due to further analysis and publication but are available from the corresponding author on reasonable request.

\section{Ethics approval and consent to participate}

The local institutional review board stated, that for this study no submission to the ethics committee is necessary (Ethik-Kommission der Bayerischen Landesärztekammer, Mühlbaurstraße 16, 81677 München ; reference number: 2019-018 fm/h). The study was performed in accordance with the ethical standards laid down in the 1964 declaration of Helsinki and its later amend ments. Informed consent of the patients or their relatives was obtained at least verbally during the initial hospital stay or during the telephone interview in the follow up because written consent was not always available in terms of the initial hospital stay or follow up. The local institutional review board approved this procedure and waived a patient informed consent, as the data is fully anonymized (Ethik-Kommission der Bayerischen Landesärztekammer, Mühlbaurstraße 16, 81677 München ; reference number: 2019$018 \mathrm{fm} / \mathrm{h})$.

\section{Consent for publication}

Not Applicable.

\section{Competing interests}

Monika Killer-Oberpfalzer is holding a research grant from Microvention Terumo unrelated to this study. Alexander Hammer, Frank Erbguth, Matthias Hohenhaus, Christian M. Hammer, Hannes Lücking, Markus Gesslein, HansHerbert Steiner and Hendrik Janssen declare no competing interests.

\section{Author details}

${ }^{1}$ Department of Neurosurgery, Paracelsus Medical University, Breslauer Straße 201, 90471, Bavaria, Nuremberg, Germany. ${ }^{2}$ Department of Neurology, Paracelsus Medical University, Breslauer Str. 201, 90471, Bavaria, Nuremberg, Germany. ${ }^{3}$ Department of Anaesthesiology, Paracelsus Medical University, Breslauer Str. 201, 90471, Bavaria, Nuremberg, Germany. ${ }^{4}$ Department of Anatomy 2, University of Erlangen-Nuremberg, Universitätsstraße 19, 91054, Bavaria, Erlangen, Germany. ${ }^{5}$ Department of Neuroradiology, University of Erlangen-Nürnberg, Schwabachanlage 6, 91054 Erlangen, Germany. ${ }^{6}$ Department of Orthopaedics and Traumatology, Paracelsus Medical University, Breslauer Str. 201, 90471, Bavaria, Nuremberg, Germany. ${ }^{7}$ Neurology/Research Institute of Neurointervention, Paracelsus Medical University, Ignaz Harrer Str. 79, Salzburg, Austria. ${ }^{8}$ Department of Neuroradiology, Ingolstadt General Hospital, Krumenauerstraße 25, 85049, Bavaria, Ingolstadt, Germany.

Received: 2 September 2020 Accepted: 12 January 2021 Published online: 19 January 2021

\section{References}

1. Kassell NF, Torner JC, Haley EC Jr, Jane JA, Adams HP, Kongable GL. The International Cooperative Study on the Timing of Aneurysm Surgery. Part 1: Overall management results. J Neurosurg. 1990;73 1:18-36. doi:https://doi. org/10.3171/jns.1990.73.1.0018.

2. Stienen MN, Germans M, Burkhardt JK, Neidert MC, Fung C, Bervini D, et al. Predictors of In-Hospital Death After Aneurysmal Subarachnoid Hemorrhage: Analysis of a Nationwide Database (Swiss SOS [Swiss Study on Aneurysmal Subarachnoid Hemorrhage]). Stroke. 2018;49(2):333-40. doi: https://doi.org/10.1161/STROKEAHA.117.019328.

3. Galea JP, Dulhanty L, Patel HC, Uk IS, Hemorrhage Database C. Predictors of Outcome in Aneurysmal Subarachnoid Hemorrhage Patients: Observations From a Multicenter Data Set. Stroke. 2017:48 11:2958-63. doi:https://doi.org/ 10.1161/STROKEAHA.117.017777.

4. Hutter BO, Kreitschmann-Andermahr I, Gilsbach JM. Health-related quality of life after aneurysmal subarachnoid hemorrhage: impacts of bleeding severity, computerized tomography findings, surgery, vasospasm, and neurological grade. J Neurosurg. 2001;94(2):241-51. doi:https://doi.org/10. 3171/jns.2001.94.2.0241.

5. Claassen J, Carhuapoma JR, Kreiter KT, Du EY, Connolly ES, Mayer SA. Global cerebral edema after subarachnoid hemorrhage: frequency, predictors, and impact on outcome. Stroke. 2002;33 5:1225-32.

6. Naidech AM, Janjua N, Kreiter KT, Ostapkovich ND, Fitzsimmons BF, Parra A, et al. Predictors and impact of aneurysm rebleeding after subarachnoid hemorrhage. Arch Neurol. 2005;62 3:410-6. doi:https://doi.org/10.1001/ archneur.62.3.410.

7. Shimoda M, Oda S, Tsugane R, Sato O. Prognostic factors in delayed ischaemic deficit with vasospasm in patients undergoing early aneurysm surgery. Br J Neurosurg. 1997;11 3:210-5.

8. Lo BW, Fukuda H, Nishimura Y, Farrokhyar F, Thabane L, Levine MA. Systematic review of clinical prediction tools and prognostic factors in aneurysmal subarachnoid hemorrhage. Surg Neurol Int. 2015;6:135. doi: https://doi.org/10.4103/2152-7806.162676.

9. Taufique Z, May T, Meyers E, Falo C, Mayer SA, Agarwal S, et al. Predictors of Poor Quality of Life 1 Year After Subarachnoid Hemorrhage. Neurosurgery. 2016;78(2):256-64. doi:https://doi.org/10.1227/NEU.0000000000001042. 
10. Molyneux A, Kerr R, International Subarachnoid Aneurysm Trial Collaborative G, Stratton I, Sandercock P, Clarke M, et al. International Subarachnoid Aneurysm Trial (ISAT) of neurosurgical clipping versus endovascular coiling in 2143 patients with ruptured intracranial aneurysms: a randomized trial. J Stroke Cerebrovasc Dis. 2002;11 6:304-14. doi:https://doi.org/10.1053/jscd. 2002.130390.

11. Spetzler RF, McDougall CG, Zabramski JM, Albuquerque FC, Hills NK, Russin JJ, et al. The Barrow Ruptured Aneurysm Trial: 6-year results. J Neurosurg. 2015;123 3:609-17. doi:https://doi.org/10.3171/2014.9.JNS141749.

12. Krishnamurthy S, Kelleher JP, Lehman EB, Cockroft KM. Effects of tobacco dose and length of exposure on delayed neurological deterioration and overall clinical outcome after aneurysmal subarachnoid hemorrhage. Neurosurgery. 2007;61 3:475 - 80; discussion 80 - 1; doi:https://doi.org/10. 1227/01.NEU.0000290892.46954.12.

13. Pobereskin LH. Influence of premorbid factors on survival following subarachnoid hemorrhage. J Neurosurg. 2001;95 4:555-9. doi:https://doi. org/10.3171/jns.2001.95.4.0555.

14. Dasenbrock HH, Rudy RF, Rosalind Lai PM, Smith TR, Frerichs KU, Gormley WB, et al. Cigarette smoking and outcomes after aneurysmal subarachnoid hemorrhage: a nationwide analysis. J Neurosurg. 2018;129(2):446-57. doi: https://doi.org/10.3171/2016.10.JNS16748.

15. Hammer A, Steiner A, Ranaie G, Yakubov E, Erbguth F, Hammer CM, et al. Impact of Comorbidities and Smoking on the Outcome in Aneurysmal Subarachnoid Hemorrhage. Sci Rep. 2018;8 1:12335; doi:https://doi.org/10. 1038/s41598-018-30878-9.

16. Dasenbrock HH, Rudy RF, Smith TR, Guttieres D, Frerichs KU, Gormley WB, et al. Hospital-Acquired Infections after Aneurysmal Subarachnoid Hemorrhage: A Nationwide Analysis. World Neurosurg. 2016;88:459-74. doi: https://doi.org/10.1016/j.wneu.2015.10.054.

17. Frontera JA, Fernandez A, Schmidt JM, Claassen J, Wartenberg KE, Badjatia $\mathrm{N}$, et al. Impact of nosocomial infectious complications after subarachnoid hemorrhage. Neurosurgery. 2008;62 1:80 - 7; discussion 7; doi:https://doi. org/10.1227/01.NEU.0000311064.18368.EA.

18. Wartenberg KE, Schmidt JM, Claassen J, Temes RE, Frontera JA, Ostapkovich $\mathrm{N}$, et al. Impact of medical complications on outcome after subarachnoid hemorrhage. Crit Care Med. 2006;34 3:617 - 23; quiz 24.

19. Stienen MN, Visser-Meily JM, Schweizer TA, Hanggi D, Macdonald RL, Vergouwen MDI, et al. Prioritization and Timing of Outcomes and Endpoints After Aneurysmal Subarachnoid Hemorrhage in Clinical Trials and Observational Studies: Proposal of a Multidisciplinary Research Group. Neurocrit Care. 2019;30(Suppl 1):102-13. doi:https://doi.org/10.1007/s12028019-00737-0.

20. Hammer A, Steiner A, Kerry G, Ranaie G, Baer I, Hammer CM, et al. Treatment of ruptured intracranial aneurysms yesterday and now. PLoS One. 2017;12 3:e0172837. doi:https://doi.org/10.1371/journal.pone.0172837.

21. Hammer A, Steiner A, Kerry G, Ranaie G, Yakubov E, Lichtenstern D, et al. Efficacy and Safety of Treatment of Ruptured Intracranial Aneurysms. World Neurosurg. 2017;98:780-9. doi:https://doi.org/10.1016/j.wneu.2016.07.013.

22. Hammer A, Ranaie G, Erbguth F, Hohenhaus M, Wenzl M, Killer-Oberpfalzer $M$, et al. Impact of Complications and Comorbidities on the Intensive Care Length of Stay after Aneurysmal Subarachnoid Haemorrhage. Sci Rep. 2020; 10 1:6228; doi:https://doi.org/10.1038/s41598-020-63298-9.

23. Hammer A, Ranaie G, Yakubov E, Erbguth F, Holtmannspoetter M, Steiner $\mathrm{HH}$, et al. Dynamics of outcome after aneurysmal subarachnoid hemorrhage. Aging. 2020;12; doi:https://doi.org/10.18632/aging.103069.

24. Huttner HB, Schwab S. Malignant middle cerebral artery infarction: clinical characteristics, treatment strategies, and future perspectives. Lancet Neurol. 2009;8(10):949-58. https://doi.org/10.1016/S1474-4422(09)70224-8.

25. Schirmer CM, Ackil AA Jr, Malek AM. Decompressive Craniectomy. Neurocrit Care. 2008;8 3:456-70. doi:https://doi.org/10.1007/s12028-008-9082-y.

26. Sarov M, Guichard JP, Chibarro S, Guettard E, Godin O, Yelnik A, et al. Sinking skin flap syndrome and paradoxical herniation after hemicraniectomy for malignant hemispheric infarction. Stroke. 2010;41 3: 560-2. doi:https://doi.org/10.1161/STROKEAHA.109.568543.

27. Wagner S, Schnippering H, Aschoff A, Koziol JA, Schwab S, Steiner T. Suboptimum hemicraniectomy as a cause of additional cerebral lesions in patients with malignant infarction of the middle cerebral artery. J Neurosurg. 2001;94 5:693-6. doi:https://doi.org/10.3171/jns.2001.94.5.0693.

28. Alexander P, Heels-Ansdell D, Siemieniuk R, Bhatnagar N, Chang Y, Fei Y, et al. Hemicraniectomy versus medical treatment with large MCA infarct: a review and meta-analysis. BMJ Open. 2016;6 11:e014390. doi:https://doi.org/ 10.1136/bmjopen-2016-014390.

29. Creutzfeldt CJ, Tirschwell DL, Kim LJ, Schubert GB, Longstreth WT Jr, Becker KJ. Seizures after decompressive hemicraniectomy for ischaemic stroke. J Neurol Neurosurg Psychiatry. 2014;85 7:721-5. doi:https://doi.org/10.1136/ jnnp-2013-305678.

30. Juttler E, Unterberg A, Woitzik J, Bosel J, Amiri H, Sakowitz OW, et al. Hemicraniectomy in older patients with extensive middle-cerebral-artery stroke. N Engl J Med. 2014;370 12:1091-100. doi:https://doi.org/10.1056/ NEJMoa1311367.

31. Juttler E, Hacke W. Early decompressive hemicraniectomy in older patients with nondominant hemispheric infarction improves outcome. Stroke. 2011; 42 3:843-4. doi:https://doi.org/10.1161/STROKEAHA.110.603597.

32. van der Worp HB, Kappelle L. Early decompressive hemicraniectomy in older patients with nondominant hemispheric infarction does not improve outcome. Stroke. 2011;42 3:845-6. doi:https://doi.org/10.1161/STROKEAHA. 110.603605.

33. Guresir E, Raabe A, Setzer M, Vatter H, Gerlach R, Seifert V, et al. Decompressive hemicraniectomy in subarachnoid haemorrhage: the influence of infarction, haemorrhage and brain swelling. J Neurol Neurosurg Psychiatry. 2009;80 7:799-801. doi:https://doi.org/10.1136/jnnp.2008.155630.

34. Guresir E, Schuss P, Vatter H, Raabe A, Seifert V, Beck J. Decompressive craniectomy in subarachnoid hemorrhage. Neurosurg Focus. 2009;26 6:E4. doi:https://doi.org/10.3171/2009.3.FOCUS0954.

35. Ponfick M, Wiederer R, Nowak DA. Outcome of Intensive Care UnitDependent, Tracheotomized Patients with Cerebrovascular Diseases. J Stroke Cerebrovasc Dis. 2015;24 7:1527-31. doi:https://doi.org/10.1016/j. jstrokecerebrovasdis.2015.03.021.

36. Brain Trauma F, American Association of Neurological S, Congress of Neurological S, Joint Section on N, Critical Care AC, Bratton SL, et al. Guidelines for the management of severe traumatic brain injury. IV. Infection prophylaxis. J Neurotrauma. 2007;24(Suppl 1):26-31. doi:https://doi. org/10.1089/neu.2007.9992

37. Szeder V, Ortega-Gutierrez S, Ziai W, Torbey MT. The TRACH score: clinical and radiological predictors of tracheostomy in supratentorial spontaneous intracerebral hemorrhage. Neurocrit Care. 2010;13 1:40-6. doi:https://doi. org/10.1007/s12028-010-9346-1.

38. Huttner HB, Kohrmann M, Berger C, Georgiadis D, Schwab S. Predictive factors for tracheostomy in neurocritical care patients with spontaneous supratentorial hemorrhage. Cerebrovasc Dis. 2006;21 3:159-65. doi:https:// doi.org/10.1159/000090527.

39. Benes VR, Jurak L, Brabec R, Nechanicka N, Sercl M, Endrych L, et al. Causes of poor outcome in patients admitted with good-grade subarachnoid haemorrhage. Acta Neurochir (Wien). 2017;159 3:559-65. doi:https://doi.org/ 10.1007/s00701-017-3081-8.

40. Fugate JE, Rabinstein AA, Wijdicks EF, Lanzino G. Aggressive CSF diversion reverses delayed cerebral ischemia in aneurysmal subarachnoid hemorrhage: a case report. Neurocrit Care. 2012;17 1:112-6. doi:https://doi. org/10.1007/s12028-012-9723-Z

41. Lu J, Ji N, Yang Z, Zhao X. Prognosis and treatment of acute hydrocephalus following aneurysmal subarachnoid haemorrhage. J Clin Neurosci. 2012;19 5:669-72. doi:https://doi.org/10.1016/j.jocn.2011.06.032.

42. Wong GK, Poon WS, Boet R, Chan MT, Gin T, Ng SC, et al. Health-related quality of life after aneurysmal subarachnoid hemorrhage: profile and clinical factors. Neurosurgery. 2011;68 6:1556-61. doi:https://doi.org/10.1227/ NEU.0b013e31820cd40d. discussion 61.

43. Poon WS, Ng SC, Wong GK, Wong LY, Chan MT. Chronic hydrocephalus that requires shunting in aneurysmal subarachnoid haemorrhage [a-SAH]: its impact on clinical outcome. Acta Neurochir Suppl. 2008;102:129-30.

44. Taran S, Trivedi V, Singh JM, English SW, McCredie VA. The Use of Standardized Management Protocols for Critically III Patients with Nontraumatic Subarachnoid Hemorrhage: A Systematic Review. Neurocrit Care. 2020;32 3:858-74. doi:https://doi.org/10.1007/s12028-019-00867-5.

45. Hernandez-Duran S, Salfelder C, Schaeper J, Moerer O, Rohde V, Mielke D, et al. Mechanical Ventilation, Sedation and Neuromonitoring of Patients with Aneurysmal Subarachnoid Hemorrhage in Germany: Results of a Nationwide Survey. Neurocrit Care. 2020. doi:https://doi.org/10.1007/s12028-020-01029-8.

\section{Publisher's Note}

Springer Nature remains neutral with regard to jurisdictional claims in published maps and institutional affiliations. 